\title{
A Qualitative Analysis of Altruism (Selflessness): Views of Headmasters in Turkey
}

\author{
Nail Yıldırım \\ Correspondence: Assoc. Prof., Nail Yıldırım, Gaziosmanpasa University, Faculty of Education Tokat, Turkey.
}

Received: March 9, 2016 Accepted: March 30, 2016 Online Published: April 7, 2016

doi:10.11114/jets.v4i7.1442 URL: http://dx.doi.org/10.11114/jets.v4i7.1442

\begin{abstract}
Being an educationist necessitates having many values. One of these values is altruism. In this study conducted on the altruism phenomenon, the dimensions of altruism demonstrated by a key group of educationists, namely the headmasters, and the reasons motivating their altruistic behavior were investigated. The aim is to create awareness around the altruism phenomenon in education. For this purpose, the study group includes 17 altruist / selfless headmasters working in Turkey. The findings of the study showed that the headmasters demonstrated altruistic behaviors because of personal reasons, the desire to solve problems, ideals, the fear of failure, the image of the school, and valor. It is observed that managing a school necessitates altruistic behavior; however, headmasters are affected negatively in this process. Such negative effects could sometimes be associated with health or social life. Building on the fact that altruism is learnable and applicable, the paper contributes positively to educating people by creating awareness around this phenomenon.
\end{abstract}

Keywords: Altruism (selflessness), educationists

\section{Introduction}

Education is a service provided to humans by humans in order to help humans gain humanistic characteristics. This service is provided with various altruistic behaviors of the providers. Altruism (selflessness) is defined as giving up desires, wishes, wants, and valuables for the sake of something (Oncul, 2000), achieving something using one's own efforts and resources (Eroglu, 2008), and focusing on helping people without expecting anything in return (Waddell, 2006). Altruism is considered as one of the schemes in the self within the personality pattern. The following characteristics are observed in an altruistic personality: selfless, swift, consistent, providing detailed answers and assessments, charitable, supportive, and able to demonstrate altruistic behavior in the future (Aydin, 1996). Indicating that altruism can be learned, Batson (1991) suggested that this could be achieved by showing sensitive and empathetic behavior towards people. Altruism is also considered to be about social awareness (Toremen, 2011).

The habitat is the source of life for the people living there, in order for them to learn about life. The concept of altruism is observed in various examples. One of the most striking examples is concerned with octopuses. The motherhood of octopus is nothing like the motherhood of any other living being. Female octopus finds a cavern and settles inside it. She starts laying eggs and broods them after she finishes laying eggs. She arranges the eggs on the ceiling of the nest as if they are hanged on a hook. She continuously blows water on the eggs to keep them clean. She never leaves the nest for anything. If she cannot stand the hunger until the eggs hatch, she eats a few of her arms. Because octopus' eggs are tantalizing to other living beings, she stays alive until all eggs hatch and protects the eggs. However, the long-lasting incubation period leaves her hungry and exhausted. She dies in her nest after all eggs are hatched and the baby octopuses are out. The dead body of the octopus becomes a food source for the young just starting their lives. That is why, none of the female octopuses witness their young to grow (Albayrak, 2015). This example is an indicator of the selflessness of a mother, giving up her own life for her children.

Altruism is observed to have a significant place in the Turkish culture. Altruism element is emphasized in the stories of Dede Korkut (Sengul, 2008). In those stories, sons of masters play an important role in the story line by undertaking a "heroic" identity after sacrificing themselves for their family or the society in which they live (Karakas, 2012). Altruism is observed to be among the important characteristics that were reflected in Ataturk's life as well (Ataturkculuk, 1993). Based on this fact, it can also be suggested that altruism is a characteristic property of heroes in the Turkish culture.

Altruism is considered to be a characteristic to be had alongside all processes and dimensions of the life (Confucius, 
1988: 50, 106, 107). One of these processes is the professional life, which is the teaching profession for the educationists. In Ataturk's education understanding as well, the teacher is the most altruist and respectable person within the society (Kocabas, 2008). The teaching profession necessitates to have many values: honesty, industriousness, openness, fairness, egalitarianism, being scientific, altruism, respecting humanity, and volunteerism, etc. (Yilmaz, 2006; Ozbek, Kahyaoglu, Ozgen, 2007). According to the study of Ekiz and Kocyigit (2013), based on the metaphors used by teachers, it is concluded that the teaching profession is perceived to be performed with responsibility, altruism, and charitable behavior. In previous studies, the teachers themselves are observed to state that the profession requires altruism (Ekiz, Kocyigit, 2013; Ozbek, Kahyaoglu, Ozge, 2007). Teachers stated that they "fully agreed" with the altruism dimension of organizational citizenship and indicated that they acted altruistically in their profession (Argon and Algan, 2013). It is considered to be worthy of investigating how much the teachers have internalized the concept of altruism. A study by TUSIAD (1991) shows that the most important thing for $9.8 \%$ of the full-time employed people in Turkey is their profession (Baltas, 2013). If this ratio is at a similar level in education, then it would be difficult to conclude that all teachers have internalized the altruism concept.

There are some relationships between management processes and altruism. Altruism is determined to serve as a dimension of leadership (Patterson, 2003). Indicating that personal sacrifices of charismatic leaders lead to loyalty of their followers, Kurel (2001) explains the leadership secret of Vehbi Koc as not hesitating to show altruistic behavior for the sake of his beliefs and aims. Similarly, it is reported that altruistic behavior solves the problem in conflict management within organizations (Eren, 1991). In conflict management, it is observed that the managers demonstrate self-sacrifice (Yildizoglu and Burgaz, 2014). There is a relationship between altruism and organizational loyalty. Self-sacrifice affects organizational commitment and loyalty of the employees (Ozkaya, Karakoc and Kaya, 1989). According to Costa and Mc Crae (1989), altruism is considered to be a business value and they include it as the first element of the business values inventory that they have developed. Altruism is also observed to be associated with organizational citizenship. Sportsmanship is cited among the dimensions of organizational citizenship, which is focused on the individual's behavior within the organization (Podsakoff, Mackenzie, Moorman, and Fetter, 1990). A sportsman individual sacrifices himself / herself for a group or for his / her own organization (Karabey, Iscan, 2007). Therefore, it could be suggested that a sportsman individual self-sacrificing himself / herself is engaging in organizational citizenship behavior.

Altruistic behavior is quite extensively observed in the management of education services. The school environment is a key, strategic, and indispensable element of the education system since the core service of the education system is produced in the school (Celikten 2008). The management is regarded as a concept as old as the history of human race that necessitates group work, brings along an administrative structure and organization, trying to find solutions to problems. One of the most important tasks of school administrators is to produce efficient solutions to the problems encountered. A headmaster is the most important person who will lead the process to reach the highest productivity that can be achieved from an educational institution and can facilitate to realize this success (Celikten, 2003). Headmastership is an exhausting task (Yaman, Bayrakci, Yaman, 2002). In a study by Yildirim (2011), headmastership was found to have negative health implications such as psychological and physiological disorders in headmasters. The negative effects of headmastership were listed as health, time, professional deterioration, family, psychological regression, and physiological decline.

In the education system, there are not only headmasters that demonstrate altruistic behavior but also headmasters that do not behave altruistically or even criticize those that are behaving altruistically. As is the case for all areas of life, the activities that help reach an aim necessitate certain altruistic behavior. This is the case in educational organizations as well. There are education professionals who show extremely altruistic behavior in the education system. The subject of this study is the investigation of the views of headmasters who demonstrate altruistic behavior. This research is necessary because it will develop an awareness around the altruism concept, it will elicit the characteristics of altruistic managers, and it will contribute to training programs in that respect. For this purpose, in the research, answers to the following questions are sought:

When the opinions of headmasters who demonstrate altruistic behavior are analyzed;

- What are the types of altruistic behavior observed in administration of education services?

- What are the managerial activities that enable altruistic behavior?

- What are the factors motivating headmasters to behave altruistically?

\section{Method}

\subsection{Research Design}

In the study, views of headmasters that demonstrate altruism / self-sacrifice were analyzed. In this research that is 
designed in line with the qualitative research approach, phenomenology pattern was utilized. In the phenomenology pattern, we focus on a phenomenon around which there is a general awareness but which are not necessarily known in detail (Yildirim and Simsek, 2008). The phenomenon that is investigated in-depth in the study is altruism. The study investigates different types of altruistic behavior shown by headmasters, the underlying reasons for altruistic behaviors, and the managerial activities that enable such altruistic behavior. In line with this, headmasters who are considered to be altruistic have been identified and requested to answer a predetermined set of questions around altruistic behavior.

\subsection{Study Group}

The study group comprises 17 altruistic headmasters working in preschools, primary schools, secondary schools, and high schools. In accordance with the qualitative research tradition, criterion sampling method was used to identify altruistic / selfless headmasters. The key aspect of criterion sampling is to study all situations that satisfy a series of predetermined criteria. Such criteria can be set by the researcher (Yildirim and Simsek, 2008). The following criteria were determined by the researcher to identify the altruistic / selfless headmasters that should be included in the study group: 1. Headmasters that are accepted by the practitioners to demonstrate altruistic / selfless behavior. For this purpose, a list of altruistic / selfless headmasters was compiled in accordance with the views of the city / district national education managers and deputy managers as well as teachers. 2 . The researcher designed criteria for altruistic behavior based on the literature. These criteria are: Willingness to give up those that are valuable and his / her desires for the sake of tasks at school (Oncul, 2000; 895); undertaking tasks using his / her own resources and efforts (Eroglu, 2008); focusing on helping people without expecting anything in return (Waddell, 2006), (the criteria here refers to the profile of an educationist who has touched the lives of others); social consciousness (Toremen, 2011) (for this purpose, undertaking socially responsible projects in school). When only the first criterion was considered, the list included 32 headmasters who showed altruistic behavior. Taking into account the second criterion, the list was reduced to 19 headmasters. Due to the fact that two headmasters were not willing to take part in the study, 17 headmasters were interviewed in the end. The characteristics of headmasters included in the study group are presented in Table 1.

Table 1. The characteristics of headmasters included in the study group

\begin{tabular}{|c|c|c|c|c|c|c|c|c|c|c|}
\hline ID & Gender & & School & & & & Seniority & Seniority & $\begin{array}{l}\text { Location } \\
\text { school }\end{array}$ & of the \\
\hline & Female & Male & Preschool & $\begin{array}{l}\text { Primary } \\
\text { School }\end{array}$ & $\begin{array}{l}\text { Secon } \\
\text { dary } \\
\text { Scho }\end{array}$ & $\begin{array}{l}\text { High } \\
\text { Scho } \\
\text { ol }\end{array}$ & (teaching) & $\begin{array}{l}\text { (managem } \\
\text { ent) }\end{array}$ & $\begin{array}{l}\text { Village } \\
\text { / town }\end{array}$ & $\begin{array}{l}\text { City } \\
\text { District }\end{array}$ \\
\hline 1 & & $\mathrm{x}$ & & $\mathrm{x}$ & & & 17 & 6 & $\mathrm{x}$ & \\
\hline 2 & & $\mathrm{x}$ & & & $\mathrm{x}$ & & 14 & 5 & & $\mathrm{x}$ \\
\hline 3 & & $\mathrm{x}$ & & & $\mathrm{x}$ & & 15 & 4 & $\mathrm{x}$ & \\
\hline 4 & $\mathrm{x}$ & & $\mathrm{x}$ & & & & 9 & 3 & & $\mathrm{x}$ \\
\hline 5 & & $\mathrm{x}$ & & & & $\mathrm{x}$ & 17 & 7 & & $\mathrm{x}$ \\
\hline 6 & & $\mathrm{x}$ & & & & $\mathrm{x}$ & 15 & 6 & & $\mathrm{x}$ \\
\hline 7 & $\mathrm{x}$ & & & & & $\mathrm{x}$ & 24 & 9 & & $\mathrm{x}$ \\
\hline 8 & & $\mathrm{X}$ & & $\mathrm{x}$ & & & 16 & 7 & & \\
\hline 9 & & $\mathrm{x}$ & & $\mathrm{x}$ & & & 13 & 4 & & \\
\hline 10 & & $\mathrm{x}$ & & $\mathrm{x}$ & & & 19 & 6 & & \\
\hline 11 & & $x$ & & $\mathrm{x}$ & & & 18 & 8 & & $\mathrm{x}$ \\
\hline 12 & & $\mathrm{x}$ & & & $\mathrm{x}$ & & 11 & 3 & & $\mathrm{x}$ \\
\hline 13 & & $\mathrm{x}$ & & & $\mathrm{x}$ & & 17 & 7 & $\mathrm{x}$ & \\
\hline 14 & & $\mathrm{x}$ & & & & $\mathrm{x}$ & 29 & 14 & & $\mathrm{x}$ \\
\hline 15 & & $\mathrm{x}$ & & & $\mathrm{x}$ & & 18 & 6 & & $\mathrm{x}$ \\
\hline 16 & & $\mathrm{X}$ & & $\mathrm{X}$ & & & 16 & 7 & & $\mathrm{x}$ \\
\hline 17 & & $\mathrm{x}$ & & $\mathrm{x}$ & & & 13 & 3 & & $\mathrm{x}$ \\
\hline
\end{tabular}

Two of the headmasters in the study group are female and 15 are male. One of the headmasters is employed in a preschool, seven are employed in a primary school, five are employed in a secondary school, and four are employed in a high school. The teaching experience of the headmasters ranges between 9 and 29 years. The management experience of the headmasters ranges between 3 and 14 years. Three of the headmasters are working in a village or a town while 14 of them are working in the center of the city or the district.

\subsection{Data Collection Tool}

In order to analyze the views of altruistic / selfless headmasters, a semi-structured interview form prepared by the researcher was used. Prior to preparing interview questions, a literature review was conducted on national and international research papers and both qualitative and quantitative research studies on the topic were used in the preparation process. During the research, no study was found to be focusing directly on the altruism phenomenon in education. Expert opinion was sought on the questions included in the interview form from three academics two of whom were experts in education management and inspection, and one in psychological counseling and guidance; and 
from two headmasters. Interview questions were piloted with one headmaster. Following these stages, the interview form was finalized based on the information obtained and the interview questions were shared with the participants. The interviews were conducted with the help of written communication and using an interview form. Data collection process lasted four months and each interview took approximately 45 minutes to complete.

\subsection{Data Analysis}

The study has a qualitative research design. Data were described accordingly. In the analysis process, initially the interview recordings were transcribed and analyzed. Views of headmasters were examined using the content analysis technique. Whilst analyzing the headmasters' views, their statements were grouped and categorized in accordance with their similarity to each other. In the analyses, the headmasters and their statements were coded $(* \mathrm{M}$; Headmaster) to generate certain themes. The data obtained from the interviews were quantified and the frequency of themes were identified. The validity and the reliability of the research was ensured as follows: (a) the research process was explained in detail from the preparation of the data collection tool to the application and the analysis, and a sufficient number of headmasters who worked altruistically and selflessly in their profession participated in the research; (b) the results were shared with the participants and their views on the results were taken into consideration; (c) other researchers who are experts in the field were requested to create themes and coded the participants' views from the raw data (in this aspect of the study it was observed that the content created by the researcher and the expert was quite similar) and hence the results were verified; (d) direct quotations from headmasters showing altruistic behavior were included in the analysis of their views; (e) the entire study process was explained in detail; (f) the findings were compared to the results of other studies in the same field (Yildirim and Simsek, 2008).

\section{Findings}

In this section, the types of altruistic behavior shown by headmasters, managerial activities associated with this altruistic behavior, and the reasons for behaving altruistically are presented respectively.

\subsection{The Types of Altruistic (Selfless) Behavior Demonstrated by the Headmasters}

Table 2. The types of altruistic (selfless) behavior demonstrated by the headmasters

\begin{tabular}{|c|c|c|c|}
\hline ID & Themes & Coded altruism sub-themes & $\mathrm{f}$ \\
\hline 1 & Material altruism & Using own body (M3, M5, M9, M14) & 4 \\
\hline 2 & & Using own finances (M5, M1, M8) & 3 \\
\hline 3 & & Using own vehicle (M2, M4, M7) & 3 \\
\hline 4 & & Using own belongings (M1, M17) & 2 \\
\hline 5 & $\begin{array}{l}\text { Psychological } \\
\text { altruism }\end{array}$ & Compromising own personality (M3, M6, M8, M9, M11, M12) & 6 \\
\hline 6 & & Humanistic situations (M9, M10, M12, M13, M14) & 5 \\
\hline 7 & & Encountered unhappiness (M3, M14, M15) & 3 \\
\hline 8 & & Empathy (M4, M7) & 2 \\
\hline 9 & Time altruism & $\begin{array}{l}\text { Not being able to spare time to himself / herself (M1, M2, M4, M7, M11, } \\
\text { M17) }\end{array}$ & 6 \\
\hline 10 & & $\begin{array}{l}\text { Allocating majority of his / her time to school's tasks (M1, M3, M4, M5, } \\
\text { M8) }\end{array}$ & 5 \\
\hline 11 & & Not having any time left for his / her hobbies (M4, M8, M9) & 3 \\
\hline 12 & & Neglecting personal development (M6, M16) & 2 \\
\hline 13 & & Constantly restarting certain tasks (M6) & 1 \\
\hline 14 & & Neglecting physical exercise (M17) & 1 \\
\hline 15 & Relationship altruism & Neglecting his / her own family (M1, M3, M8, M9, M11, M14, M17) & 7 \\
\hline 16 & & Neglecting friends (M5, M6, M11) & 3 \\
\hline 17 & & Using his / her own network for the school (M7, M9) & 2 \\
\hline 18 & & Neglecting relatives (M12, M13) & 2 \\
\hline 19 & Health altruism & Psychological wears (M2, M3, M7, M8, M9, M13, M15, M16, M17) & 9 \\
\hline 20 & & Physiological wears (M2, M7, M8, M11, M12, M16) & 6 \\
\hline 21 & & Deterioration of health (M3, M13) & 2 \\
\hline
\end{tabular}

In line with the views of headmasters, the types of altruistic behavior are categorized under five themes (material, psychological, time, relationship, and health) and 21 subthemes. Under the material altruism theme, headmasters indicate that they sacrifice their body, vehicle, money, and belongings. In terms of "material" altruism, headmasters' own statements are as follows: "When buying reference books for students, we personally buy reference books for those students who are economically disadvantaged (M5)". "The tasks at the school are not finished by the close of business and the shuttle leaves. Then I have to return home using another means of transport. I pay both for the shuttle and the additional means of transport (M8)". "I could not find anybody to do the landscaping of the school; therefore, I had to do it myself (M11)". "When I was first appointed at this school, everything was a problem. For four years I had shown all types of altruism. I always sacrificed myself. In the end I was able to make things right. One of the problems that I 
had the greatest difficulty was related to convincing people about the service. Now I am appointed to another school. I know I have to start over (M6)". When these statements are analyzed, it is observed that headmasters show material altruism intensively.

According to the views of the headmasters, the second type of altruism is "psychological" altruism. Headmasters state that they psychologically sacrifice by compromising their personality, empathizing with others, helping out in humanistic situations, and experiencing unhappiness. Headmasters' own statements in line with psychological altruism are as follows: "We compromised our pride; we asked, we begged for money (M6, M8)". "I sacrificed something that is absolutely non-existent in my job description. I had done almost everything for a female teacher to not get divorced. In the end, I succeeded (M10)". "The headmaster sacrifices his / her image the most. I was not able to please anybody irrespective of how much I tried. In the end I was stigmatized with the "bad headmaster" image (M12)". "As a person who loved the teaching profession, I was very pleased with what I was doing. After having been appointed as a headmaster, I no longer get any satisfaction from my job (M15)". "In the end I started begging the school's attendant (M9)". "The face of the student beaten by his father haunted me for days (M7)". "The situation of a female student kept me awake at nights (M14)". "Only God and I know what I have been through (M8)". "I was stressed to death (M7, M9, M14)". "I no longer had a smile on my face (M7)". "I did not know whether I lived on the earth or in the heavens (M11)". "I just wanted to curl up and die (M12, M15)". "I have never had so much difficulty in my life (M6)". "Chills ran up and down my spine (M6)". As can be understood from these statements the headmasters are subject to psychological wear in their line of business.

As another type of altruism, the headmasters indicate sacrificing their own time for their profession. As part of "time" altruism, they mention not being able to spare time for themselves, not being able to find time for their hobbies, constantly restarting the tasks, and not being able to spare time for physical exercise or personal development. In line with time altruism, the headmasters' statements are as follows: "Somebody had to be on duty and there were no volunteers among the teachers. I remember being on duty for 26 nights in a month in order not to delay the tasks (M5)". "We have gone to the school at the weekends (M4)". "That summer we renovated everything in the school. It took 10 years out of my life. I never forget that summer (M8)". "I can no longer find time to read a book (M16)". "As a person who used to walk regularly, I can no longer have a walk in the evenings (M17)". As can be understood from these statements, the headmastership is an education service that takes a lot of time outside the working hours.

As another type of altruism, the headmasters mention "relationship" altruism. The headmasters indicate that they neglect their family, relatives, and friends. The headmasters' statements in accordance with the relationship altruism are as follows: "As a result of intensive studies, my students managed to secure a place in a good high school. However, my own daughter was not as successful. In fact, my daughter had great potential. If I were able to attend to the needs of my daughter as I did for my students, she could have been accepted to a good high school (M9)". "We were paying visits to parents and warning them about the Internet and the television. Three weeks later, I arrived home one evening to find out that my son was surfing on the Internet and my daughter was watching television at an inappropriate hour (M9)". "I have to spare time for important days of people in the school's circles. However, I cannot spare time for the special days of my own relatives and close friends (M11)". "Due to an activity taking place at school I was not able to keep any of my promises I had given to my family (M3)". "I no longer see my friends as frequently as before (M11)". "There are times I cannot be with my relatives on their good days and bad days (M12)". It could be understood from these statements that the headmastership affects relationships with the family, relatives, and friends negatively.

The last type of altruism demonstrated by the headmasters is organized under the "health" theme. The headmasters indicate that they are worn out psychologically and physiologically and state the following: "I neglected my illness in order to finish my tasks. When I had to go to the hospital, I was diagnosed with pneumonia. My right lung still works at 75\% (M3)". "I have a stressed, uneasy, and frantic professional life (M3, M14)". "I did something that was not my job for the sake of serving the education system. I was staying late at work until 11pm at night. I had to answer to many managers. My family life was upside down. However, there was no compensation for my altruism. I was under investigation for tasks that I was not responsible for. An investigation should not have been the result of my sacrifices. The current ulcer problem I have, had started at that time (M3)". "My school was the top school in the city but I was burnout (M2)". "I remember suffering severely high temperatures at night yet going to the school in the morning (M13)". "My color had become absolutely white (M14)”. "I have a stomach ache ever since then (M3)". "My blood pressure jumped up to 18 (M6)". "I have become diabetic (M14)". As can be understood from the above statements, the headmasters have to sacrifice their health as well. 


\subsection{Managerial Activities Where Headmasters Show Altruistic Behavior}

Table 3. Managerial activities where headmasters show altruistic behavior

\begin{tabular}{llll}
\hline ID & Theme & Coded Categories & Frequency \\
\hline 1 & Technique & School's physical tasks (M2, M3, M4, M6, M7, M8, M9, M11, M13, M15, M16, M17) & 12 \\
2 & & Problem solving (M1, M2, M3, M4, M6, M7, M8, M12, M14, M16, M17) & 11 \\
3 & Activities (M2, M6, M7, M9, M11, M12) & 6 \\
4 & Implementing legislation (M6, M8, M9, M11, M12) & 5 \\
5 & Activities outside the line of work (M1, M3, M7, M9, M12) & 5 \\
6 & Conflict management (M2, M5, M11, M14) & 4 \\
7 & Teaching tasks (M5, M7, M9) & 3 \\
8 & Meetings (M6, M17) & 2 \\
9 & Additional tasks (M5, M16) & 2 \\
\hline 10 & Humanistic & Parent visits (M1, M2, M4, M6, M7, M11, M17) & 7 \\
11 & & Activities to convince personnel (M4, M7, M11) & 3 \\
\hline
\end{tabular}

According to the headmasters who participated in the study, their managerial activities can be investigated under technical and humanistic themes in 11 different areas. School's physical tasks appear to be the area with the highest level of altruistic behavior. The following statement of a headmaster summarizes many things: "I built the boiler room of the school myself. However, after 10 days, I had to undergo a hernia operation (M14)". Another altruistic activity is associated with problem solving. Some views of the headmasters in relation to problem solving are as follows; "The teachers bring every problem to me (M2, M16)". "Sometimes a problem remains unsolved for months (M2, M4)”. From these statements it is understood that headmasters behave altruistically whilst solving problems as well. Another managerial activity is related to (social) activities. A headmaster indicates; "I took the students to Istanbul for an activity. That trip cost me a lot (M1)". From this statement and Table 3, it could be concluded that activities inside and outside the school are also performed altruistically. In a similar manner, implementing the legislation, activities outside the line of work, conflict management, teaching tasks, meetings, additional tasks, parent visits, and efforts to convince personnel are also considered to be activities that necessitate altruistic behavior. Some examples from the headmasters' statements in relation to those managerial activities that necessitate altruistic behavior are as follows: "During the meetings of the top management, I am constantly listening to the phone to ring. I constantly fear that there will be a problem (M11)", "I visited one particular parent nine times in order to convince him to send his child to the school. I succeeded in the end (M14)". As can be understood from Table 3 and the quoted statements of the headmasters, all managerial processes that are carried out for the school necessitate some level of altruism.

\subsection{The Reasons for Headmasters to Behave Altruistically (Selflessly)}

Table 4. The reasons for headmasters to behave altruistically (selflessly)

\begin{tabular}{|c|c|c|c|}
\hline ID & Themes & Coded reasons for altruism & Frequency \\
\hline 1 & Personal & $\begin{array}{l}\text { Efforts to succeed (M1, M2, M3, M4, M6, M7, M8, M9, M11, M12, M13, M15, M16, } \\
\text { M17) }\end{array}$ & 14 \\
\hline 2 & & Ideals (M1, M2, M3, M4, M5, M6, M7, M8, M9, M10, 12, M15, M16, M17) & 14 \\
\hline 3 & & $\begin{array}{l}\text { Thinking of himself / herself at first (M1, M2, M3, M4, M6, M7, M8, M9, M11, M12, M13 } \\
\text { M16, M17) }\end{array}$ & 13 \\
\hline 4 & & Fear of failure (M1, M3, M5, M6, M8, M10, M11, M13, M15, M16, M17) & 11 \\
\hline 5 & & The importance of education (M2, M4, M5, M7, M9, M10, M13, M15, M16) & 9 \\
\hline 6 & & Ideals of Education Service (M1, M2, M4, M6, M9, M11, M13, M15, ) & 8 \\
\hline 7 & & Character (Personality) (M1, M6, M7, M9, M12, M17) & 6 \\
\hline 8 & & Being an exemplar to contribute to the solution (M6, M7, M12, M14, M16) & 5 \\
\hline 9 & Prevention & Prevention of failure (M1, M2, M3, M5, M6, M7, M9, M11, M12, M13, M15, M16, M17) & 13 \\
\hline 10 & & Prevention of ineptness (M2, M4, M6, M8, M9, M11, M13, M15) & 8 \\
\hline 11 & & Prevention of further growth of negativity (M2, M6, M8, M9, M11, M13, M15, M17) & 8 \\
\hline 12 & & $\begin{array}{l}\text { Prevention of negativity from damaging the school's image (M1, M4, M5, M7, M11, M13, } \\
\text { M16, M17) }\end{array}$ & 8 \\
\hline 13 & & Prevention of problems from being heard by others (M3, M4, M7, M10, M11, M17) & 5 \\
\hline 14 & & Prevention of cascading the problems to the top management (M4, M5, M10, M11) & 4 \\
\hline 15 & $\begin{array}{l}\text { The nature of the } \\
\text { problem }\end{array}$ & $\begin{array}{l}\text { The desire to eliminate the problem (M1, M2, M3, M6, M7, M8, M9, M10, M11, M12, } \\
\text { M13, M15, M16, M17) }\end{array}$ & 14 \\
\hline 16 & & $\begin{array}{l}\text { Eliminating the problem from the system as soon as possible (M2, M6, M7, M8, M9, M10, } \\
\text { M13, M14, M15) }\end{array}$ & 9 \\
\hline 17 & & $\begin{array}{l}\text { Problem solving perception of employees (the solution is with the headmaster) (M3, M8, } \\
\text { M10, M11, M13, M17) }\end{array}$ & 6 \\
\hline 18 & & Covering up the problem (M9, M13, M17) & 3 \\
\hline
\end{tabular}

According to the headmasters who participated in the study, the reasons for behaving altruistically can be categorized under three groups as "personal", "prevention", and "the nature of the problem" with 18 sub-themes. The headmasters put forward "efforts to achieve personal success" and "fear of failure" as the first reason for demonstrating altruistic 
behavior. A headmaster stated: "I have accepted this task, therefore I must be successful in achieving it (M17)", and another asserted: "I must make sure others do not deem me unsuccessful". Judging from these statements, it is understood that the altruistic behavior is originating from the need to succeed. Another personal reason for behaving altruistically is observed to be the ideals. Moreover, the fact that the headmasters think of themselves in the first place is considered a reason for altruistic behavior. The following statement of a headmaster could be explained by his / her excessive responsibilities: "I blame myself if one of my students stumbles and falls whilst walking on the road (M15)". Headmasters also consider the importance of education a reason for showing altruistic behavior. The majority of the headmasters emphasized the importance of education; one of them stated: "A human becomes a human owing to the education. That is why we should do our job (M8)". Another indicated: "The biggest reason for the world's problems is the failure of education to achieve its aim (M9)". Another commented: "If it were to happen again now, I would do the same (M7)". All of these statements are evidence for the importance of education as an underlying reason for altruistic behavior.

When the views of headmasters on altruism are analyzed, it is observed that there are some elements of valor. It could be said that this is related to culture. It is understood from the altruistic headmasters' views that some of the altruistic behavior was not voluntary but compulsory. The following statements of the headmasters suggest that they had to behave altruistically because of being out of options: "In fact, it is not my job to drive students with my car to the movie theater but I feel like I have to (M7)". Another assertion: "It is not my job to repair the roof of the school but when I cannot find anyone else to do it, I have to do it myself (M15)". It is also concluded from the following statement that the headmasters would behave even more altruistically but they hesitate: "When taking the students to another village close by, the tire blew out. God forbid nothing happened. Who would have protected me if something had happened? (M17)"

According to the headmasters, another main category of reasons for behaving altruistically is prevention. The headmasters think that they behave altruistically because they want to prevent failure, ineptness, prevent others and the top management from learning about problems in order to prevent damage to the school's image. Some of the statements of the headmasters are as follows: "After having learned about a letter one student wrote to another, I had to closely monitor the students for days and convince many people in order for this to be not become widely known around the school's social circles (M13)". "Only I know how much I suffer to prevent fights among teachers with different worldviews (M11)". "This society does not question the reasons behind failure. I continue sacrificing anything in order to prevent being deemed unsuccessful by others (M5)'. As can be seen from the above statements as well, preventing or mitigating negative incidents is considered as a reason for behaving altruistically.

Another reason for the altruistic behavior of headmasters is observed to be the nature of the problem. According to the headmasters, resolving problems within a system and mitigating negative consequences of a problem and the assumption that problems are only solved by the headmaster necessitate working in an altruistic fashion. Several of the statements put forward by the headmasters are as follows: "There is a problem with the teachers in terms of the perception of an issue. Headmasters are expected to resolve all kinds of problems. That is why, I feel I have to behave altruistically in order to meet the expectations (M8)". "If we cannot resolve the problem as soon as possible, I will harm myself and bring damage to the school. That is why it is necessary to sacrifice certain things (M11)". "I did not know what to do (M13)". As can be seen from these statements, problem-solving necessitates altruistic behavior.

\section{Results, Discussion and Suggestions}

In this study, which investigated the altruism phenomenon, the views of headmasters who behave altruistically was investigated. In order to assess the altruistic behavior, certain criteria have been developed based on the literature by the researcher. It was quite difficult to select the headmasters according to these criteria. That is because it was not easy to find headmasters that satisfied the criteria for altruistic behavior.

As can be concluded from the findings of the research, there are different types of altruistic behavior. Concepts such as time altruism or relationship altruism are observed to be experienced in school management. Managerial activities that necessitate altruistic behavior are rather related to the technical and the humanistic aspects of the job at hand. Moreover, personal characteristics, the nature of the problem, and the desire to prevent negative consequences are the reasons behind headmasters' altruistic behavior. In addition to these, the following results can be discussed based on the findings of the research:

It is observed that the headmasters think that they behave altruistically because of their ideals about the education service. This concept reminds the idealist teachership. Duymaz (2014) defines idealist teachers as the "workers of light". In the "Heartache" movie within the Turkish genre, examples of an idealist teacher's sacrifices from himself, his daughter's health and the altruistic behavior shown to others are presented. In the movie, the teacher's response to his daughter when she questions his altruistic behavior is: "I am the victim of my ideals. Presently, I would have done the same if it had happened again. I do not know why it is like this. Knowingly volunteering to suffer..." statement shows 
that the main reason behind altruistic behavior is a person's ideals and the headmasters appear to have a similar view. Ruggieri and Abbate (2013) found that selfsacrificial leaders are prepared to abandon everything including personal gains, privileges or enrichment for the betterment of the organization. In fact, these types of leaders may use their own resources such as their private time to perform tasks for the organization.

Altruistic headmasters are idealists and they have a high loyalty to the organization. This result is similar to the results reported by Yazicioglu and Topaloglu (2009) that as the commitment of employees increases, it becomes easier for them to adopt organizational aims and to internalize the organizational aims, increasing their emotions around behaving altruistically. As a result of the study, it is observed that the headmasters behave altruistically in conflict management as well. This result appears to be in line with the conclusion in the study by Yildizoglu and Burgaz (2014) that; "in case of a conflict, headmasters take into account the expectations of the people involved and strive for these people to leave the conflict with the minimum loss possible". In terms of the school management, the manager's solving the problems by behaving altruistically may result in gradually losing his / her authority over his / her subordinates (Yildizoglu, Burgaz, 2014).

Headmasters are observed to behave altruistically to protect the image of the school. Doe (2005) cited in Altun and Kirkit (2005) indicates that negative image created about the school puts additional pressure on the headmasters, affects the morale of the personnel negatively, and distresses families. The result of this study as well justifies the altruistic behavior of the headmasters.

The headmasters are observed to demonstrate altruistic behaviors to eliminate a problem as soon as possible. This result can be explained by the fact that Turkish people have low tolerance for uncertainty (Baltas, 2013). It is observed that the desire to eliminate uncertain situations originating from a problem is one of the reasons for behaving altruistically. The headmasters could benefit from functional training on problem-solving to develop professionally in analyzing problems accurately and making informed decisions. That is because primary school managers in our country have poor problem-solving skills according to Bozkurt and Ustun (2003). Personal efforts of headmasters appear to be more prominent than other aspects in solving students' problems (Yildirim, 2011).

When the views of headmasters on altruism are analyzed, it is observed that there are some elements of valor. It is a fact that, there is a need for altruistic behaviors in a developing country. In this respect, initiatives can be exercised in educational activities of headmasters and these initiatives can be formally recognized in corresponding legislations.

When the views of the headmasters are analyzed, the personal characteristics of altruistic headmasters can be listed as follows: Focused on success, fearing failure, idealist, thinking of themselves first under a situation that necessitates altruistic behavior, striving to be a good example (or the desire to show valor), believing in the importance of education, having proactive (education) service ideals, endeavoring to eliminate problems, and being motivated to prevent the school image from harm.

The above listed characteristics of altruistic headmasters are also the characteristics of leadership. In continuous professional development trainings to be offered to headmasters on leadership (leadership in teaching, leadership in education), altruism can be offered as a separate subject area. The concept of altruism is evident in the Turkish culture (Sengul, 2008; Karakas, 2012). That is why it is necessary to benefit from this important value of the Turkish culture. Since altruism can be learned (Batson, 1991), the people that are trained to be educationists can be introduced to the concept of altruism during their undergraduate studies or can be exposed to this concept through continuous professional development trainings that are offered on the job.

It is observed that the altruistic behavior is backbreaking. The professional wear of headmasters could be formally recognized in the legislations. The headmasters are also observed to spare their time for the school's social circles. Such times allocated to school out of the working hours can be scored and included in the performance assessment of headmasters. It is observed that managing a school necessitates altruistic behavior; however, headmasters are affected negatively in this process. Such negative effects could sometimes be associated with health or social life. The Turkish history is full of various types of altruistic behavior. Activities such as including altruism in the trainings, organizing competitions on altruistic behavior, or awarding people who behave altruistically could increase the awareness around the concept of altruism and motivate other education professionals to show altruistic behavior as well.

\section{References}

Albayrak, F. (2015). Sacrifice and motherhood. http://e-koc.org/item/441-fedakarlik-ve-annelik. Erişim tarihi ve saati, 11 .

Altun, A. S., \& Kirkit, G. (2005). School principals'şmages in the printed media. Educational Administration: Theory and Practice, 41(24-46).

Argon, T., \& Alğan, Y. (2013). Organizational citizenship behaviors and problem solving skills of primary school 
teachers. Journal of Abant İzet Baysal University, 13(1), 142-163.

Atatürkçülük (1983). Kemalist thought system. Third Edition. Ankara: Genel Kurmay Başkanlığı Yayını.

Aydın, B. (1996). Self concepts and 'I' schemes . M.Ü. Atatürk Journal of Educational Sciences, 8, 41-47.

Baltaş, A. (2013). Management in Turkish Culture. 6. Basım. Remzi kitabevi.

Batson, C. D. (1991). The altruism question: Toward a social-psychological answer. Hillsdale, NJ: Erlbaum.

Bozkurt, E., \& Üstün, A. (2003). Professional factors affecting the problem solving capability of school managers based on their own perceptions Kastamonu Education Journal, 11(1), 13-20.

Çelikten, M. (2003). A portrail of an ideal school. Eurasian Journal of Educational Research, 13, 139-162.

Costa, P. T. Jr., \& Mc Crae, R. R. (1992). NEO-PI-R. Professional manual. Odessa, FL: Psychological Assessment Resource.

Duymaz, R. (2014). Ídealist teacher, İstanbul: Akademik kitaplar

Ekiz, D., \& Koçyiğit, Z. (2013). Exploring primary school teachers' metaphors concerning 'teacher'. Kastamonu Education Journal, 21(2), 439-458.

Eren, E. (1991). Management and organization. İstanbul: İÜ İşletme Fakültesi Yayınları.

Eroğlu, A. M. (2008). Language of moral values in society. International Congress of Social Scientists. 22-24 Ekim 2008 Kirgizistan.

Karabey, C. N., \& İşcan, Ö. F. (2007). The relationship between organizational identification, organizational image and organizational citizenship behaviour. Ataturk University Journal of Economics and Administrative Sciences, 21(2), 231-241.

Karakaş, R. (2012). The characteristics and fucntions of the sons of tribe leaders in Dede Korkut stories. Journal of Çukurova University Institute of Social Sciences, 21(1), 155-168.

Kirel, Ç. (2001). A new approach on the formation of leadership behaviour: From Charismatic leadership to transformational leadership. Anadolu University Journal of Social Sciences, 1, 43-59.

Kocabaş, A. (2008). Philosophical foundations of turkish education system: Dewey, Mustafa Necati and İsmail Hakkı Tonguç. Society and Democracy, 2(3), 203-212.

Konfüçyüs, (1988). Söyleşimler, çev. İsmail Akyıldız,İstanbul: Gün Yayıncılık.

Öncül, R. (2000). Glossary of training and education science. İstanbul: MEB.

Özbek, R., Kahyaoğlu, M., \& Özgen, N. (2007). Evaluation of candidate teachers' opinions on teaching profession. Journal of Social Sciences, 9(2), 221-232.

Özkaya, M. O., Kocakoç, İ. D., \& Karaa, E. (2006). Examining the relations between demographic factors and managers organizational commintment: A field study. Management and Economy, 13(2), 78-98.

Patterson, K. (2003). Servant Leadership: A Theoretical Model. Proceedings of the Servant Leadership Roundtable. Retrieved January, 13, 2009.

Podsakoff, P. S., MacKenzie, M. R., \& Fetter, R. (1990). Transformational leader behaviors and their effects on followers' trust in leader, satisfaction, and organizational citizenship behavior. Leadership Quarterly, 1, 107-142. http://dx.doi.org/10.1016/1048-9843(90)90009-7

Ruggieri, S., \& Abbate, S. C. (2013). Leadership style, self-sacrifice, and team identification. Social Behavior and Personality, 7(41), 1171-1178. http://dx.doi.org/10.2224/sbp.2013.41.7.1171

Şengül, A. (2008). Dede Korkut in Republic theatre. Turkish Studies, 3(2), $617-626$. http://dx.doi.org/10.7827/turkishstudies.313

Töremen, F. (2011). The responsibility education of teacher candidates. Educational Sciences: Theory and Practice, 11(1), 263-277.

Waddell, J. T. (2006). Servant leadership. http://www.regent.edu/acad/sls/publications/conference_proceedings/servant

Yaman, M., Bayrakçı, M., \& Yaman, Ç. (2002). The relationship between sources of stress and personality traits of managers. Eurasian Journal of Educational Research, 9, 1-15.

Yazıcığlu, İ., \& Topaloğlu, I. G. (2009). The relationship between organizational justice nd commintment: A case study in accomodation establishment. Journal of Business Research, 1(1), 3-16. 
Yıldırım, A., \& Şimşek, H. (2008). Sosyal bilimlerde nitel araştırma yöntemleri. Ankara: Seçkin.

Yildırım, N. (2011). Positive and Negative Contributions of Management Profession to School Managers. Education and Science, 36(161), 230-245.

Yıldızoğlu, H., \& Burgaz, B. (2014). The Relationship between School Administrators' Five Factor Personality Traits and Their Conflict Management Style Preferences. Hacettepe University Journal of Education, 29(2), 295-310.

Yıldızoğlu, H., \& Burgaz, B. (2014). The Relationship between School Administrators' Five Factor Personality Traits and Their Conflict Management Style Preferences. Hacettepe University Journal of Education, 29(2), 295-310.

Y1lmaz, K. (2006). Individual and organizational values according to teachers and school administrators in public primart school and how do the school administrators manage their schools according to these values. Unpublished Dissertation Thesis, Ankara University Institute of Educational Sciences.

\section{$(\mathrm{cc}) \mathrm{BY}$}

This work is licensed under a Creative Commons Attribution 3.0 License. 